\title{
Decolonizar a História da Educação: contribuições teóricas dos estudos subalternos e do pensamento decolonial
}

Decolonizing the History of Education: theoretical contributions of subaltern studies and decolonial thinking

\author{
Vitor Sousa Cunha Nery \\ Orcid: http://orcid.org/0000-0002-1309-6094 \\ Educação, Universidade do Estado do Amapá, Macapá, Amapá \\ vitor.nery@ueap.edu.br \\ Cristiane do Socorro dos Santos Nery \\ Orcid: http://orcid.org/0000-0002-1323-6069 \\ Intercultural Indígena, Universidade Federal do Amapá, Oiapoque, Amapá, \\ crisnery@unifap.br \\ Alder de Sousa Dias \\ Orcid: https://orcid.org/0000-0003-0996-0000 \\ Educação do Campo, Universidade Federal do Amapá, Mazagão, Amapá, \\ alderdiass@yahoo.com.br
}

Received on 20/07/2020 - Approved on 22/07/2020

\section{Resumo}

Neste artigo, analisa-se possíveis contribuições dos estudos subalternos e decoloniais para a pesquisa em História da Educação. Trata-se de uma pesquisa bibliográfica, fundamentada em autores como Guha (2011), Chakrabarty (2000), Spivak (2010), Beverley (2004), Mallon (1995), Dussel (2008; 2016), Quijano (2005), Mignolo (2002, 2003, 2004, 2007), Walsh (2012), Grosfoguel (2016), Streck (2007), Mota Neto (2015), entre outros. Conclui-se que a relação entre os estudos subalternos, a decolonialidade e a História da Educação tem potencial crítico para (re)interpretar dados históricos e educacionais, dando visibilidade para os grupos subalternizados.

Palavras-chave: Estudos Subalternos. Decolonialidade. História da Educação. 


\section{Abstract}

In this article, possible contributions from subaltern and decolonial studies to research in the History of Education are analyzed. This is a bibliographic research, based on authors like Guha (2011), Chakrabarty (2000), Spivak (2010), Beverley (2004), Mallon (1995), Dussel (2008; 2016), Quijano (2005), Mignolo (2002, 2003, 2004, 2007), Walsh (2012), Grosfoguel (2016), Streck (2007), Mota Neto (2015), among others. It is concluded that the relationship between subordinate studies, decoloniality and the History of Education has a critical potential to (re) interpret historical and educational data, giving visibility to subordinate groups.

Keywords: Subaltern Studies. Decoloniality. History of Education.

\section{Introdução}

A proposta de tematizar os estudos subalternos e decoloniais e a pesquisa em História da Educação parte de dois pontos fundantes. O primeiro é a percepção de que sujeitos e grupos populares têm ficado à margem de produções científicas, inclusive histórico-educacionais no contexto amazônico.

O segundo ponto fundante da pesquisa que gerou este artigo foram as leituras e reflexões feitas acerca dos estudos pós-coloniais, principalmente de historiadores indianos do "Grupo de Estudos Subalternos", do "Grupo LatinoAmericano de Estudos Subalternos" e de intelectuais da Rede "Modernidade/Colonialidade" (M/C).

A partir das quais se considera que as perspectivas epistêmicas subalternas são uma forma de conhecimento que, "vindo de baixo", origina uma crítica do conhecimento hegemônico científico, autorreferenciado em países do Ocidente, de tal modo que a narrativa hegemônica historiográfica assente no imaginário dessa porção do hemisfério foi produtora e produto da colonização. Uma geopolítica do conhecimento que gerou subalternidade de saberes, povos e culturas, resultando numa genealogia dos processos de subalternização das diferentes formas de saberes, línguas, histórias locais, memórias e costumes que foram subsumidas no contexto da colonialidade (Santos, 2009).

Motivo pelo qual, faz-se necessário (re)afirmar lugares de enunciação, que se configuram como espaço fronteiriço, como "espaço subalterno", ou seja, um pensamento que identifica o potencial do pensamento que surge da subalternidade colonial, o espaço no qual o pensamento foi negado pelo pensamento da modernidade, de esquerda ou de direita. Um "pensamento fronteiriço" que não se configura em um fundamentalismo teórico e prático, que rejeita tudo e qualquer coisa que seja europeia, mas que considera a duplicidade de consciência gerado pelo sistema-mundo colonial/moderno (Mignolo, 2003).

Desses pontos fundantes, questionamos: Que contribuições epistemológicas podem advir dos estudos subalternos e da decolonialidade à pesquisa em História da Educação?. Tendo por objetivo analisar possíveis 
contribuições epistemológicas da decolonialidade e dos estudos subalternos ao campo histórico-educacional.

A processualidade do estudo de que resulta esse artigo se deu por meio de uma pesquisa bibliográfica, fundamentada em autores como Guha (2011), Chakrabarty (2000), Spivak (2010), Beverley (2004), Mallon (1995), Dussel (2008; 2016), Quijano (2005), Mignolo (2002, 2003, 2004, 2007), Walsh (2012), Grosfoguel (2016), Streck (2007), Mota Neto (2015), entre outros.

Assim, discorremos sobre os estudos subalternos e decoloniais, seus principais conceitos e sobre produções científicas que abordam essas teorias em consonância com a História da Educação Latino-Americana. Em seguida, apontamos as discussões sobre os estudos subalternos que têm a América Latina como Lócus de Enunciação. Por fim, discutimos a decolonialidade e suas contribuições para a pesquisa histórico-educacional.

\section{Dos Estudos Subalternos à Decolonialidade: contribuições à História da Educação}

Do ponto de vista teórico, os Estudos Subalternos se inserem no campo dos estudos pós-coloniais, que em nossa compreensão remonta aos anos 1950, com Aimé Césaire em o "Discurso sobre o Colonialismo", a 1957 com Albert Memmi em o "Retrato do Colonizado precedido de retrato do colonizador" e a 1961 com Frantz Fanon a partir de "Os condenados da terra".

Nos anos 1970, na Índia, alguns pensadores, como Ranajit Guha e Gayatry Spivak, passam a utilizar o termo "subalterno" para se referir a grupos marginalizados; grupos esses que não possuem voz ou representatividade, em decorrência de seu status social. Cabe dizer que se trata de um atributo geral relacionado à subordinação da sociedade, em termos de classe, casta, idade, gênero e trabalho.

Nos anos de 1980 os Estudos Subalternos passam a ganhar mais contundência com o indiano Ranajit Guha, a partir de sua intervenção na historiografia sul-asiática. Dado que possibilitou um enfoque historiográfico dos locais dominados, até então, vistos apenas do ponto de vista dos colonizadores e seu poder hegemônico. Emergindo, assim um "grupo de pensadores indianos que se opunham ao que consideravam uma visão colonialista e elitista sobre a história da Índia" (Weinstein, 2003, p. 208). Na contramão dessa visão elitista, os olhos dos estudiosos dos Estudos Subalternos se voltaram para os grupos marginalizados e subalternizados da história da Índia.

Desse modo, enquanto se tornava um modelo para o subcontinente e, rapidamente, possibilitaria uma séria crítica ao pós-colonialismo, a produção intelectual desse grupo ensejou o debate sobre exilados, excluídos e oprimidos também em outras regiões do mundo. 
Assim, uma importante prerrogativa para o desenvolvimento do Grupo de Estudos Subalternos Sul-Asiáticos foi reescrever a trajetória da Índia colonial de um distinto e separado ponto de vista, o das "massas", promovendo uma história alternativa com relação ao discurso oficial dos historiadores que se inscreviam na ideologia de suas alianças políticas com a Raj Inglesa ${ }^{1}$.

Essa perspectiva de subalternidade se espraia para outras dimensões do existir humano, inclusive no que se refere à produção do conhecimento científico. Há séculos filósofos e pensadores que deram forma à natureza das ciências sociais produziram teorias que abarcam a totalidade da humanidade, apesar de essas declarações serem feitas em relativa ignorância a outras sociedades. Tal atitude criou um paradoxo cotidiano das ciências sociais terceiro mundistas: autores do terceiro mundo, acham essas teorias, apesar de sua inerente ignorância, eminentemente úteis para compreender as nossas sociedades (Chakrabarty, 2000).

Por exemplo, no caso de historiadores do Terceiro Mundo sentem a constante necessidade de se referirem à História europeia em seus trabalhos, enquanto que para os historiadores europeus esse é um movimento não recíproco. Eis um sintoma da posição de subalternidade epistemológica.

Nesse caso, os historiadores mais respeitados são, ao menos culturalmente, europeus no sentido de produzir seus trabalhos em relativa, senão total, ignorância às histórias não ocidentais, e isso não parece afetar a qualidade de seus trabalhos (Chakrabarty, 2000).

Outro conceito importante para os estudos subalternos é exatamente o de subalterno que de acordo com Guha (2011) pode se referir à classe, casta, idade, gênero, ocupação ou qualquer outra forma de dominação que indique uma condição de subalternidade. Spivak (2010) refere-se ao termo subalterno não apenas para designar o oprimido, mas também como forma de representação dos que não conseguem lugar de atuação na sociedade. Refere-se àquelas pessoas que não conseguem falar, se posicionar, expor sua visão de mundo. Nesse caso, a condição de subalternidade é uma condição de silêncio, já que essas pessoas não dispõem de um representante para sua condição de silenciado.

Retificar a inclinação elitista característica de grande parte da produção acadêmica é um dos principais objetivos dos estudos subalternos. Diante disso os estudos subalternos promoveram a partir de então novas pesquisas nessa perspectiva, como podemos observar no trabalho de Guha (2011) sobre as insurreições camponesas na Índia colonial, devido as leituras historiográficas elitistas simplificarem as revoltas e os seus atores políticos populares, colocandoos como elementos secundários nas tramas do poder.

Este tipo de análise seria problemática para o autor porque negaria ao camponês o reconhecimento de protagonista da sua própria história, incluindo-o apenas enquanto parte de um projeto maior, no caso, o colonialismo. Existe de acordo com o autor uma relação dialética entre dominantes e dominados. Não é possível falar de um sem levar o outro em consideração. A história não pode ser 
pensada apenas pelo ponto de vista de um único grupo. No caso das insurreições camponesas, era preciso que se "[...] reconhecesse a rebelião pelo ponto de vista dos próprios camponeses, atribuir-Ihes consciência" (Guha, 2011, p. 81).

Ao conferir um caráter político à ação do camponês, Guha (2011) valorizou esse grupo como protagonista da sua própria história, expondo a possibilidade de uma revisão historiográfica sobre o assunto. Os aspectos supracitados acima aproximaram os estudos subalternos do marxismo, especialmente da figura de Antônio Gramsci. Quando pensamos no marxismo inglês, e na concepção de História "vista de baixo", especialmente em autores como Edward Palmer Thompson e Eric Hobsbawm, é patente a aproximação entre esses campos de estudo.

Por outro lado, os estudos subalternos se afastam da vertente clássica do marxismo e de acordo com Chakrabarty (2011) uma das divergências se refere ao fato de os marxistas não separarem poder e capital. E por mais que não fossem marxistas ortodoxos, acabaram por dar maior valor às questões econômicas. Este seria um contraponto, pois, o conceito de poder para os subalternos é flexível, não precisando necessariamente ter capital atuando.

De acordo com Chakrabarty (2011), Hobsbwam em seu trabalho sobre bandidagem social e consciência atrasada, conferiu às revoltas camponesas organizadas um caráter pré-político. Para Chakrabarty (2011) ignorar a esfera política dos movimentos camponeses configurou um marxismo eurocêntrico e elitista, posto que não analisou a consciência camponesa, diferente de Guha (2011) que demonstrou que os camponeses não tinham uma consciência atrasada, pelo contrário, na medida em que buscavam destruir o poder de seu inimigo e converter sua condição de subalternidade, estavam atuando politicamente.

Outro aspecto elementar dos estudos subalternos diz respeito à valorização das questões culturais e espirituais. No intuito de desconstruir parte da historiografia tradicional e valorizar a visão subalterna, historiadores acabam por adentrar a lógica cultural das comunidades estudadas, revelando formas alternativas de se compreender a história, além de precisarem "esmiuçar" as fontes para tentar dar voz aos diferentes sujeitos históricos (Chakrabarty, 2011).

Por isso, talvez, o porquê de os estudos subalternos, segundo Mignolo (2003, p. 271), proporem "descarrilhar e perturbar a vontade dos poderosos", unidos pela preocupação de escrever a história em uma perspectiva pós-colonial, atuante e subalterna.

Para a pesquisa em História da Educação, advoga-se que os estudos subalternos podem trazer contribuições em termos teóricos e metodológicos, mas principalmente no sentido de retificar a inclinação elitistas da escrita da História da Educação, por meio de novas possibilidades de análise e de compreensão do campo educacional.

Por exemplo, tal como aponta Chakrabarty (2000), em relação à posição de subalternidade epistemológica dos historiadores do Terceiro mundo para com os 
do Primeiro Mundo, esse dado também serve para os historiadores da educação situados no Brasil em relação à, por exemplo, a Europa, pois tal como aponta Streck (2007) é preciso superar o estrangeirismo endêmico (europeizante e ianquizante) presente nas elites e nos importantes segmentos dos povos americanos. Dado que corrobora o ponto de vista de Quijano (2005, p. 274): "é tempo de aprendermos a nos libertar do espelho eurocêntrico, onde a imagem é sempre, necessariamente, distorcida, tempo, enfim, de deixar de ser o que não somos!".

Nesse sentido, em meados da década de 1990, historiadores da educação latinos (Saviani, Rama \& Weinberg, 1996), começaram a problematizar se era possível uma História da Educação Latino-Americana. Apesar da resposta afirmativa dos autores, isso só foi possível de fato quando houve a criação e consolidação dos programas de pós-graduação em Educação (PPGE), de grupos de pesquisas em História da Educação e com a realização de congressos locais, regionais, nacionais e internacionais desse campo do conhecimento.

A partir de 2010 já é possível observar uma crescente produção acadêmica sobre o objeto de uma História da Educação Latino-Americana - com ancoragens teóricas e epistemológicas distintas - conforme se exemplifica no quadro a seguir.

Quadro 1 - Algumas produções sobre História da Educação Latino-Americana

\begin{tabular}{|c|c|c|}
\hline AUTORES & ANO & TITULO \\
\hline Dermeval Saviani & \multirow{3}{*}{1996} & \multirow{3}{*}{ Por uma História da Educação Latino Americana } \\
\hline Germán Rama & & \\
\hline Gregório Weinberg & & \\
\hline José Martí & 2007 & $\begin{array}{c}\text { Educação em nossa América: textos } \\
\text { selecionados }\end{array}$ \\
\hline Danilo Streck & 2010 & $\begin{array}{l}\text { Fontes da Pedagogia Latino-Americana: uma } \\
\text { antologia. }\end{array}$ \\
\hline José Gondra & \multirow{2}{*}{011} & \multirow{2}{*}{$\begin{array}{l}\text { História da Educação na América Latina: ensinar } \\
\text { \&escrever }\end{array}$} \\
\hline José Claudio Somma Silva & & \\
\hline Claudia Alves & \multirow{2}{*}{2012} & \multirow{2}{*}{$\begin{array}{l}\text { História e Historiografia da Educação Ibero- } \\
\text { Americana: projetos, sujeitos e práticas. }\end{array}$} \\
\hline Ana Crystina Mignot & & \\
\hline João Colares da Mota Neto & 2016 & Por uma Pedagogia Decolonial na América Latina \\
\hline José Gondra & 2018 & $\begin{array}{c}\text { Imprensa Pedagógica na Ibero-América: local, } \\
\text { nacional e transnacional }\end{array}$ \\
\hline $\begin{array}{l}\text { Ana Clara Bortoleto Nery } \\
\text { Adriane Raquel Santana de Lima }\end{array}$ & 2019 & Educação para mulheres na América Latina \\
\hline Oscar Jara & 2020 & $\begin{array}{l}\text { A Educação Popular Latino Americana: História e } \\
\text { Fundamentos Éticos, Políticos e Pedagógicos }\end{array}$ \\
\hline
\end{tabular}

Fonte: Elaboração dos autores.

Considera-se que essa desconstrução de modos consolidados e hegemônicos de fazer a história, pode ser correlacionada com a pergunta que dá título ao livro de Spivak (2010): "Pode o Subalterno Falar?". Repensar hierarquias entre fontes e sujeitos da história implica em não aceitar a subalternidade do conhecimento e buscar apontamentos epistemológicos distintos desse padrão de poder.

Entre as contribuições de Spivak para a história, menciona-se sua crítica ao agenciamento da produção acadêmica, processo que leva à ilusão de 
cumplicidade do intelectual. Para a autora, o Terceiro Mundo é intraduzível para o Primeiro Mundo, e não cabe ao intelectual falar pelo subalterno. Sugere e convoca então os intelectuais, para criarem espaços em que os subalternos se articulem e sejam ouvidos, sem agenciamento.

Em relação à possibilidades para a pesquisa em História da Educação no contexto amazônico, já se percebe nos PPGE da Universidade do Estado do Pará (UEPA) e do Instituto de Ciências da Educação da Universidade Federal do Pará (UFPA) um movimento de produção historiográfico-educacional, que se abre a abordagens para além da referência eurocêntrica, com problematizações e metodologias que levem em consideração experiências educativas "outras" - no sentido da alteridade subalternizada e invisiblizada pelo padrão hegemônico de poder, inclusive científico, que se desdobra, consequentemente, na produção do conhecimento em História da Educação - e que valoriza conhecimentos pedagógicos diversos para além da educação escolar.

Perspectiva essa desses PPGE's que amplia as fontes de pesquisa, para romper com as verticalizações históricas. Procura restaurar as vozes, as experiências, as identidades, e as histórias educativas dos subalternos, em que as práticas de pesquisa dialoguem com os sujeitos e não sobre os sujeitos que fizeram e fazem outras formas de educação.

De nosso ponto de vista, considera-se que os historiadores da educação na Amazônia tem se dedicado nos últimos anos a investigar sujeitos e práticas educativas subalternas, a partir de experiências de comunidades indígenas, quilombolas, ribeirinhas, movimentos sociais rurais e urbanos, tendo a sensibilidade de dar centralidade aos sujeitos, compreendendo-os como intelectuais, produtores e intérpretes da realidade social.

Outro ponto de ancoragem da produção científica histórico-educacional está na valorização das memórias coletivas dos movimentos de resistência, pois conforme Mota Neto (2015), esses movimentos, há mais de 500 anos, têm resistido à dominação colonial, imperial, capitalista, armazenando em seus acervos seculares (e até milenares) de conhecimento uma série de estratégias de sobrevivência e enfrentamento da opressão. São conhecimentos que, apesar do "epistemicídio" promovido pela modernidade/colonialidade, resistem e são repassados de geração a geração por meio de práticas formativas muito peculiares, que infelizmente a ciência pedagógica, de dominância positivista e eurocêntrica, tem ignorado.

\section{Dos Estudos Subalternos à América Latina como Locus de Enunciação}

$\mathrm{Na}$ década de 1990, nos Estados Unidos, surgiu um Grupo Latinoamericano de Estudos Subalternos, composto por intelectuais de setores da esquerda, formado por cinco integrantes: John Beverley, Robert Carr, José 
Rabasa, Javier Sanjinés e lleana Rodrigues. Seguindo o exemplo do grupo da Índia, eles formaram outro grupo com características semelhantes, referindo-se à América Latina. Em 1993 publicaram um "Manifesto inaugural", no qual se destaca o momento histórico pós-ditatorial, com vários processos de redemocratização e a nova ordem econômica transnacional, como consequência do alinhamento das políticas neoliberais e da globalização econômica, que os fizeram buscar novas formas pensar e agir politicamente.

O Grupo Latinoamericano, segundo Mignolo (2003), consiste principalmente de críticos literários e culturais, embora inclua um historiador, um antropólogo e um cientista político - nunca foi uma questão crucial à historiografia como formação disciplinar, como nos Estudos Subalternos do Sul da Ásia.

Para Beverley (2004), a institucionalização dos Estudos Culturais nos Estados Unidos levou-o a se inclinar para esse campo, onde encontrou uma ligação satisfatória entre a pesquisa acadêmica e a política do conhecimento.

Entretanto, a historiadora chilena-americana, Florencia Mallon, volta-se para historiografia enquanto disciplina e vê com desconfiança o fato de que um grupo de latino-americanistas nos Estados Unidos, com formação principalmente em crítica literária e cultural, estarem se apropriando da contribuição do Grupo de Estudos Subalternos do Sul da Ásia, que era formado por um grupo de historiadores unidos em escrever a história da Índia em uma perspectiva póscolonial e subalterna (Mignolo, 2003).

Os latino-americanistas deram preferência epistemológica ao que chamaram os quatro cavaleiros do Apocalipse (Mallon, 1995; Rodriguez, 2001), ou seja, a Foucault, Derrida, Gramsci e Guha. Entre estes quatro, contam-se três pensadores eurocêntricos, fazendo dois deles (Derrida e Foucault) parte do cânone pós-estruturalista/pós-moderno ocidental. Apenas um, o historiador indiano, Rinajit Guha, é um pensador que pensa a partir do Sul. Ao preferirem pensadores ocidentais como principal instrumento teórico, traíram o seu objetivo de produzir estudos subalternos.

Entre as muitas razões que conduziram à desagregação do Grupo Latinoamericano de Estudos Subalternos, uma delas foi a que veio opor os que consideravam a subalternidade uma crítica pós-moderna - o que representa uma crítica eurocêntrica ao eurocentrismo - àqueles que a viam como uma crítica decolonial - uma crítica por parte dos povos e saberes silenciados e subalternizados) (Mignolo, 2003). Diante disso, o diálogo com o Grupo Latino-americano de Estudos Subalternos, tornou evidente a necessidade de transcender epistemologicamente - ou seja, de decolonizar - a epistemologia e o cânone ocidentais.

Mallon (1995), criticou o grupo latino-americano e teve um debate acalorado com um dos seus integrantes, o venezuelano, John Beverley, acusando seus membros de serem textualistas demais privilegiando a crítica de textos e esquecendo o passado, dependentes da "desconstrução" de Derrida, quando o trabalho do historiador deveria ser feito, fundamentalmente, nos arquivos e no 
trabalho de campo. Ela também os crítica por não reconhecerem as contribuições da história social não reconhecendo as contribuições da história social "desde abajo" na América Latina.

\begin{abstract}
A tentativa contraditória de "conhecer" o passado, de conhecer os seres humanos que o fizeram, nos leva através de fontes arquivísticas que se recusam a nos dar imagens claras. Mas, como os arquivos fornecem pistas extraordinárias sobre as relações de poder e os dilemas humanos, morais e filosóficos enfrentados pelos indivíduos que os produziram e aqueles cujas sombras os habitam, não podemos nos dar ao luxo de passar sem eles. Na minha experiência, é o processo em si que nos mantém honestos: sujar as mãos com a poeira dos arquivos, enlamear nossos sapatos no trabalho de campo (Mallon, 1995, p. 107).
\end{abstract}

Para Mallon (1995), tanto o arquivo quanto o campo são cenários construídos e nos quais as lutas pelo poder intervêm. Essas lutas são, em si mesmas, fontes de informação. Todos os textos são construídos, assim como a produção e preservação dos arquivos e as relações sociais que acompanham a leitura das fontes. Embora privilegie o trabalho em arquivos e no campo, não descarta textos literários.

O campo de estudo da história latinoamericana segundo Mallon (1995) vem tendendo se relacionar mais prontamente com tradições históricas e teóricas baseadas na Europa do que com as nascidas e criadas no Terceiro Mundo. Diante disso, o historiador indiano Chakrabarty (2000) afirma que escrever história implica em permanecer sob a hegemonia da Europa, sua proposta de supera-la é "Provincializar a Europa", por meio de uma historiografia da intersecção de ambos os lados da modernidade, como o Terceiro Mundo contribui para modernidade ao mesmo tempo que a modernidade produz o Terceiro Mundo, ou, de forma equivalente, como interagem no interior da diferença colonial da modernidade (Chakrabarty, 2000).

No entanto, Provincializar a Europa não é um projeto de pura rejeição a "modernidade", valores liberais, universais, razões, grandes relatos, explicações totalizantes, e assim por diante, também não significa um projeto de apoio ao relativismo cultural. O significado de Provincializar a Europa, consiste no reconhecimento de que a aquisição que a Europa fez para si do adjetivo "moderno" faz parte de uma história global cujo todo é a história do imperialismo europeu; e na compreensão de que a associação da Europa com "modernidade" não é trabalho da Europa nem dos europeus apenas: também têm parte nisso os processos nacionalistas do terceiro mundo. Por esse motivo, "Provincializar a Europa" não pode ser um projeto nacionalista, tampouco nativista (Chakrabarty, 2000).

Para tal mudança acontecer, Chakrabarty (2000) alerta que a universidade não é o local mais adequado para a promoção do projeto de desprovincializar o projeto, pois os protocolos da história acadêmica e das instituições sempre se referirão à Europa hiper-real, na qual gravita toda a imaginação histórica. Portanto, é preciso questionar a História até alcançar a criação de numa nova história que contenha todas as heterogeneidades. 
O autor faz uma extensa crítica ao historicismo, pois este método que transformou a História carrega consigo pressupostos fundamentais que permitiram a supressão de histórias e subjetividades subalternas. O naturalismo do tempo histórico pertence à crença de que tudo pode ser historicizado. No entanto, em um país como a Índia, onde os agentes sobrenaturais têm participação ativa na vida cotidiana da população, em seus lares e trabalho na forma de rituais, descartar narrativas em que os deuses são parte ativa da história, é silenciar a maioria das histórias.

A incapacidade do historicismo em traduzir histórias que não se encaixem em seu método temporal e sua visão de mundo faz com que passados que apresentem qualquer grau de "infração" a seus preceitos sejam automaticamente excluídos. São esses passados que resistem à historicização que o autor vai chamar de "passados subalternos" (Chakrabarty, 2000).

O autor coloca como grande desafio aos historiadores resgatar as histórias subalternas e manter o sujeito subalterno como sujeito da História, condição necessária para sua participação na sociedade e construção de um mundo mais plural. Esse desafio podemos estender também para os historiadores da educação para a produção e divulgação de estudos e pesquisas sobre os sujeitos silenciados pela história no contexto educacional.

As reflexões dos estudos subalternos inspiraram uma série de análises de críticos latinoamericanos na década de 1990, que deram origem ao Grupo Modernidade Colonialidade, formado por pesquisadores com pensamentos heterogêneos como, Mignolo (2003), Dussel (2008), Quijano (2010), Walsh (2012), Grosfoguel (2016), entre outros. O termo decolonial tornou-se a identidade dessa formação de pesquisadores, que conseguiram complementar e avançar no projeto epistemológico de luta, resistência e visibilidade dos subalternos.

\section{A Decolonialidade como projeto "outro" de sociedade e suas possíveis relações com a pesquisa histórico-educacional}

Diante do dilema de Chakrabarty (2000) de "Provincializar a Europa", o filósofo argentino-mexicano Enrique Dussel (2008), propõe como proposta nessa construção epistemológica a "transmodernidade", onde o termo "trans" quer dizer "além" da modernidade eurocêntrica.

\footnotetext{
Quando falo de transmodernidade estou me referindo a um projeto global que busca transcender a Modernidade da Europa e da América do Norte. Este projeto não é pósmoderno, pois a pós-Modernidade ainda é uma crítica incompleta da Modernidade, feita pelos europeus e pelos norte-americanos. A transmodernidade, ao contrário, é uma tarefa, em meu caso, expressa filosoficamente, cujo ponto de partida é aquilo que foi descartado, desvalorizado e julgado como inútil entre as culturas globais, incluindo a filosofia colonizada ou das periferias [...] (Dussel, 2008, pp.19-20).
} 
Transmodernidade indica todos os aspectos que se situam "além" (e também, cronologicamente, "anteriores") das estruturas valorizadas pela cultura euro-americana moderna, e que atualmente estão em vigor nas grandes culturas universais não europeias e foram se movendo em direção a uma utopia pluriversal.

Figura 1 - Modelo aproximado para compreender o sentido da transmodernidade

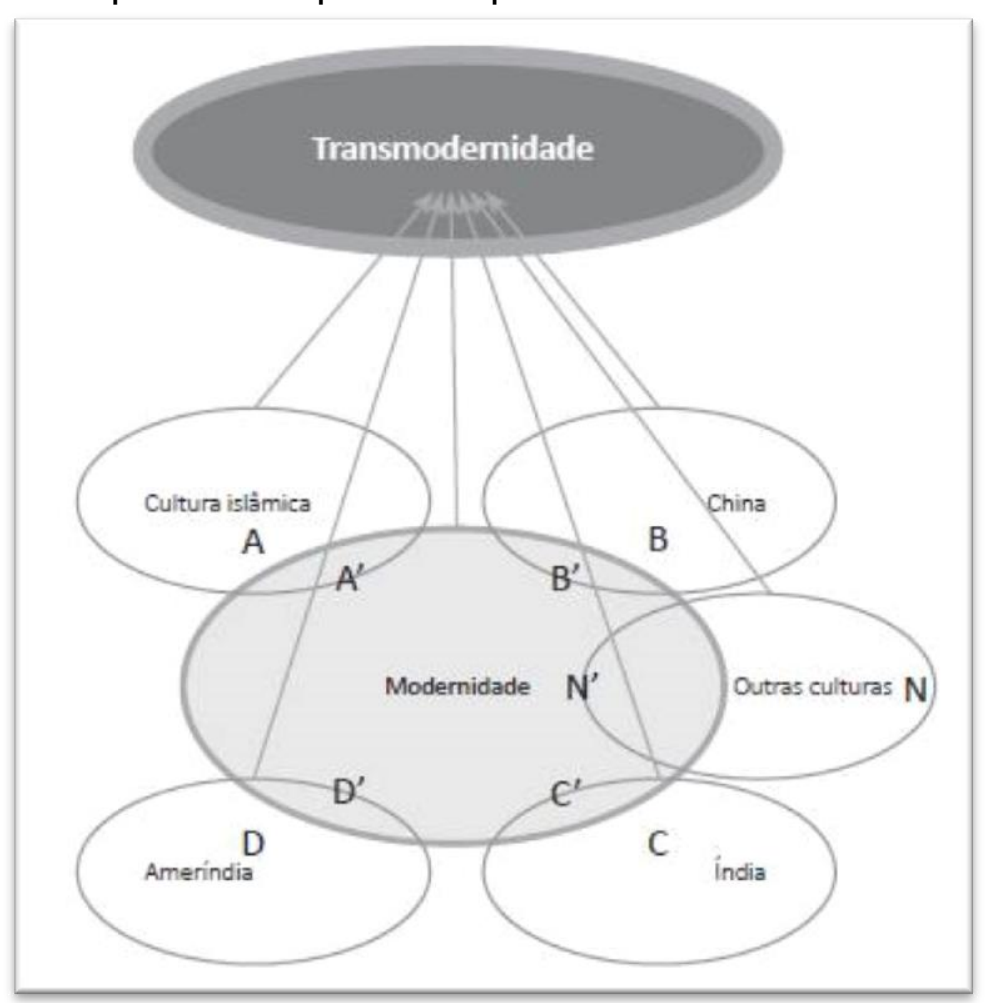

Fonte: Dussel (2016, p. 63).

A transmodernidade é um convite para que se produza, a partir de distintos projetos epistêmicos políticos que existem no mundo hoje, uma redefinição dos muitos elementos apropriados pela Modernidade eurocêntrica e tratados como inerentes à Europa, rumo a um projeto decolonial de libertação para além das estruturas capitalistas, patriarcais, eurocêntricas, modernas e coloniais. A transmodernidade clama por uma pluralidade de soluções, onde "muitos decidem por muitos". A partir de diferentes tradições epistemológicas e culturais surgirão também respostas diferentes para os mesmos problemas (Grosfoguel, 2016).

Chakrabarty e Dussel parecem concordar que a modernidade não é necessariamente e apenas a Europa ocidental, e a Europa não é a sede do conhecimento porque conhecimento é produzido em toda parte. Quando Chakrabarty reconhece o problema e propõe "Provincializar a Europa" como um projeto para atuar no sentido da de-subalternização do conhecimento, Dussel propõe um projeto transmoderno que atuará na interseção e na contribuição planetária para construir a pluriversidade, sem ignorar as relações de poder, ou, como diria Quijano, a colonialidade do poder. 
A pretensa superioridade do saber europeu, nas mais diversas áreas da vida, foi um importante aspecto da colonialidade do poder no sistema-mundo colonial/moderno. Os saberes subalternos foram "[...] excluídos, omitidos, silenciados e/ou ignorados" (Grosfoguel, 2008, p. 136). Os europeus foram buscar muito do seu conhecimento utópico nos sistemas históricos não ocidentais que encontraram nas colônias, apropriando-se deles e tornando-os parte fundamental de sua modernidade eurocentrada.

Nesse sentido Mignolo (2003) propõe o pensamento de fronteira, como resposta epistêmica do subalterno ao projeto eurocêntrico da modernidade. Ao invés de rejeitarem a modernidade para se recolherem num absolutismo fundamentalista, as epistemologias de fronteira subsumem/redefinem a retórica emancipatória da modernidade a partir das "cosmologias e epistemologias do subalterno", localizadas no lado oprimido e explorado da diferença colonial, rumo a uma luta de libertação descolonial em prol de um mundo capaz de superar a modernidade eurocentrada. (Grosfoguel, 2008, p. 138).

Neste mesmo direcionamento, com o objetivo de romper com o racismo epistêmico da modernidade em diálogo com o pensamento eurocêntrico, muito embora não tenha por suposição eliminar nem mesmo negar o conhecimento gerado desde o Norte Global, Walsh (2012), propõe uma interculturalidade epistêmica, traduzida como um projeto político e epistemológico de intervenção na realidade social que considera e revisa aspectos históricos da colonização, recolocando e retomando a história desde outra perspectiva e outros referenciais, apontando para aquilo que Quijano (2010) denomina como horizonte de sentido histórico. Tal horizonte pode ser pensado por meio de perspectivas que de fato considerem outras alternativas epistemológicas, uma vez que necessariamente, contesta a estrutura colonial e racial de poder, privilegiando saberes outros, para além do reducionismo e da generalização do projeto de saber eurocêntrico. Todo horizonte de sentido histórico é uma combinação epistêmica, teórica, histórica, ética, estética e política (Quijano, 2010).

A partir da obra "Histórias Locais/Projetos Globais: colonialidade, saberes subalternos e pensamento liminar", Mignolo (2003), nos instiga a pensar na relevância dos estudos decoloniais latinoamericanos para a História e para História da Educação. Os saberes e as histórias locais europeias foram tomados como projetos globais, criando-se um imaginário dominante do sistema mundo colonial/moderno.

A diferença colonial (física e imaginária) é tida natural como parte da ordem universal, onde há uma subalternização de saberes povos e culturas. Para questionar essa ordem o autor propõe o pensamento liminar/crítico com a valorização dos saberes subalternos, onde pensamento liminar é o espaço onde as histórias locais adotam, integram, adaptam, rejeitam ou ignoram os projetos globais (Mignolo, 2003).

O reconhecimento e a compreensão da diferença colonial, bem como, da subalternidade epistemológica são fundamentais para o que Mignolo (2003) denomina de pensamento liminar realizado "nas e a partir das margens" (p.30). 
Maneira de pensar que não é inspirada em suas próprias limitações e não pretende dominar e humilhar; uma maneira de pensar que é universalmente marginal, fragmentária e aberta; e, como tal, uma maneira de pensar não etnocida.

O pensamento liminar abre espaço para o reconhecimento da diferença colonial, pode possibilitar a abertura de espaços para a emergência de vozes, línguas, culturas, significados, histórias antes excluídas, silenciadas ou nomeadas tão somente por suas carências. Traz à tona a polifonia, a pluralidade de possibilidades do conhecer e do ser, nenhuma tendo necessidade de eliminar a outra para se afirmar. $O$ exercício de tal pensamento leva à reflexão além da interpretação, da tradução da perspectiva ocidental hegemônica, podendo constituir ruptura epistemológica, criativa, original, libertadora. Segundo Mignolo (2003), o pensamento liminar desenvolve-se nas fissuras da colonialidade, constrói-se no diálogo com os saberes hegemônicos, mas a partir de saberes que foram subalternizados nos processos imperiais coloniais.

Nesse contexto, a história da educação brasileira é uma construção cultural complexa, gestada em um contexto dotado de determinadas características sociohistóricas decoloniais, carregados de colonialidades, mas que a epistemologia de uma perspectiva histórica hegemônica produz uma narrativa da modernidade dissociada do ponto de vista do subalterno. No entanto de acordo com Shueler (2014), é preciso reconhecer que na historiografia especializada, a categoria "educação" ainda mantém profundos vínculos com certas perspectivas criadas pelo pensamento iluminista. Alimentada pela perspectiva ilustrada que naturalizou o viés civilizatório da educação formal, a historiografia brasileira mais tradicional quase sempre atentou exclusivamente para os projetos escolares estatais, que foram concebidos e administrados pelas elites letradas e proprietárias. Neles, os "de baixo" sempre aparecem como meros consumidores de produtos culturais "alienantes", impostos pela classe dominante. No entanto, não estamos nem de longe propondo o abandono dos estudos sobre a escola como instituição de educação, em seus moldes mais clássicos. Entretanto, é necessário avançar na proposição de novos olhares sobre o mesmo problema de pesquisa, bem como novos objetos e abordagens (Shueler, 2014).

A história da educação escolar foi, em grande parte, ensinada nos princípios epistemológicos do colonizador branco, masculino, racional, cristão e heteronormativo europeu. Fazemos um ensino de história que invisibiliza os conhecimentos e saberes dos povos indígenas, afro-brasileiros, quilombolas, ciganos, camponeses, ribeirinhos, etc. A escola, de modo geral, tem contribuído para uma sociedade calcada em práticas preconceituosas e discriminatórias quando, em boa parte das aulas, não problematiza o currículo eurocentrado, branco e racista, masculino, cristão (Oliveira, 2012).

A genealogia do pensamento educacional brasileiro foi construída sobre as bases de uma colonialidade pedagógica europeia, justificada pela sistemática violência da chamada "missão civilizatória"; na negação da identidade racial e étnica do colonizado e no abandono forçado de saberes e práticas da cultura local. Enfrentar a colonialidade pedagógica, significa aprender com a história que 
produziu culturas e conhecimentos, mas sem repetir e copiar servilmente o que se produz no Norte. (Streck, Adams \& Moretti, 2010).

Os colonizadores preocuparam-se em destruir imaginários, invisibilizar sujeitos para que, assim, pudessem afirmar seu próprio imaginário. Para tanto, foi preciso reprimir e destruir "[...] os modos de produção de conhecimentos, saberes, do mundo simbólico, de imagens, que são próprios do colonizado e impõem outros" (Oliveira \& Candau, 2013, p.279, tradução nossa). Utilizaram-se de múltiplas estratégias para naturalizar e internalizar um pensamento único, racional, moderno, cristão dos europeus como sendo o único correto e, então, construíram a "[...] a subalternização epistêmica do outro não europeu e a negação e esquecimento de processos históricos não europeus" (Oliveira \& Candau, 2013, p.279, tradução nossa).

A educação deve dialogar com a história, no sentido de que os homens e as mulheres a produzem, não conforme as suas escolhas, mas a partir das situações ou circunstâncias dadas ou transmitidas do passado. Neste sentido, a separação entre história e educação seria a certeza de que a educação capitalista cria e transmite valores que dão legitimidade aos interesses dominantes como se outras alternativas não fossem possíveis e de que a história, como consequência, devesse ser constantemente adulterada para a sustentação destes interesses (Streck, Adams \& Moretti, 2010).

Desse modo, não há como negar o "legado" da modernidade que chegou como imposição na América Latina e em especial na área da Educação com a colonialidade pedagógica, mas é necessário reconhecê-la e contextualizá-la histórica e epistemologicamente por meio da História da Educação.

Os estudos e pesquisas em História da Educação com perspectivas decoloniais nos cursos de formação de professores, podem contribuir com o rompimento das colonialidades presentes em nossa sociedade que começam a ser ensinadas em sala de aula desde a educação básica, onde os currículos supervalorizam a cultura europeia branca, heterossexual, cristã e masculina e inferiorizam e subalternizam outros povos, em especial os indígenas e africanos. De nossa parte, considera-se que as colonialidades presentes nos cursos de formação de professores influenciam práticas pedagógicas e ações no contexto da educação escolar.

Tais conhecimentos histórico-educacionais em perspectiva subalternodecoloniais podem e devem ser divulgados nos diversos ambientes educativos, desde os movimentos sociais, como espaços de luta e resistência em vista de uma sociedade justa e transmoderna, a ambientes da educação escolar básica, assim como no âmbito da formação de professores. 


\section{Conclusões}

O objetivo deste texto foi analisar possíveis contribuições dos estudos subalternos e da decolonialidade para a pesquisa em História da Educação. Realizou-se uma incursão teórico-reflexiva a partir de temas debatidos pelo Grupo de Estudos Subalternos Indianos, Grupo Latino Americano de Estudos Subalternos e Rede M/C.

Estudos e pesquisas em História da Educação ancorados nos referenciais teóricos subalternos e decoloniais podem contribuir: como forma de revelar as colonialidades presentes em nossa sociedade, inclusive nos espaços educativos; para a formação de professores a partir da (re)leitura de fontes e sujeitos no ensino da disciplina História da Educação; e, na proposição de projetos de formação para além do meio acadêmico, com práticas educativas nas escolas públicas e movimentos sociais, procurando valorizar e reconhecer vozes e experiências educativas "outras".

Motivo pelo qual se faz necessário ampliar os estudos e pesquisas em comunidades indígenas, quilombolas, ribeirinhas, movimentos sociais, mantendose a sensibilidade de dar centralidade aos sujeitos subalternizados, muitos destes, profissionais da área da educação.

Considera-se que os estudos subalternos e decoloniais podem contribuir epistemologicamente para pensar o campo da História da Educação, por meio de possibilidades de análise e de compreensão de dimensões da Educação normalmente negadas e silenciadas pela colonialidade. Longe de se esgotar a temática, ressalta-se que os estudos subalternos e decolonialidade tem potencial crítico para (re)interpretar dados históricos contribuindo com pesquisas no campo da História da Educação, dando visibilidade para os grupos sociais subalternizados.

\section{Referências}

Beverly, John. (2004). Subalternidad y Representación: debates en teoría cultural. Madrid, Espanha: Iberoamericana Vervuert.

Chakrabarty, Dipesh. (2011). Estudios subalternos e historiografía postcolonial. In Freire, Raúl Rodríguez (Comp.). La (re)vuelta de los Estudios Subalternos. Una cartografía a (des)tiempo, Antofagasta. Santiago, Chile: Ocho Libros/Universidad Católica del Norte, 334-357.

Chakrabarty, Dipesh. (2000). Provincializing Europe. Postcolonial Thought and Historical Difference. Princeton: Princeton University Press.

Dussel, Enrique. (2008). Meditaciones anti-cartesianas: sobre el origen del antidiscurso filosófico de la Modernidad. Tabua Rasa, Bogotá, Colômbia, 9, 153-197. 
Dussel, Enrique. (2016). Transmodernidade e interculturalidade: interpretação a partir da filosofia da libertação. Soc. Estado, Brasília, 31(1).

Grosfoguel, Ramón. (2008). "La opción decolonial: desprendimiento y apertura. Um manifiesto y un caso". Tabula Rasa, Bogotá,Colômbia, 8, 243-282.

Grosfoguel, Ramón. (2016). A estrutura do conhecimento nas universidades ocidentalizadas: racismo/sexismo epistêmico e os quatro genocídios/epistemicídio do longo século XVI. Revista Sociedade e Estado, Brasília, 31(1).

Guha, Ranajit. (2011). Prefácio a los estudos subalternos. In Freire, Raúl Rodríguez (comp.). La (re)vuelta de los Estudios Subalternos. Una cartografía a (des)tiempo, Antofagasta. Santiago: Ocho Libros, Universidad Católica del Norte, 69-79.

Mallon, Florencia. (1995). Promesa y dilema en los estudios subalternos: perspectivas a partir de los estudios latino-americanos, Boletín del Instituto de Historia Argentina y Americana Dr. E. Ravignani, FFyL-FCE, Buenos Aires, Argentina, 12, 87-116.

Mignolo, Walter. (2003). História locais / Projetos globais: colonialidade, saberes subalternos e pensamento liminar. Belo Horizonte, Brasil: UFMG.

Mota Neto, João Colares da. (2015). Educação popular e pensamento decolonial latino-americano em Paulo Freire e Orlando Fals Borda. Tese de Doutorado, Universidade Federal do Pará, Instituto de Ciências da Educação, Programa de Pós-Graduação em Educação, Belém, Pará, Brasil.

Oliveira, Luiz Fernandes. (2012). História da África e dos africanos na escola: desafios políticos, epistemológicos e identitário para a formação dos professores de História. Rio de Janeiro, Brasil: Imperial Novo Milênio.

Oliveira, Luiz Fernandes de \& Candau, Vera Maria ferrão. (2013). Pedagogía decolonial y educación anti-racista e inter-cultural en Brasil. In Walsh, Catherine (Org.) Pedagogías decoloniales: prácticas insurgentes de resistir, (re)existir y (re)vivir. Tomo I. Quito, Ecuador: Ediciones Abya Yala, 273-303.

Quijano, Anibal. (2005). Colonialidade do Poder, Eurocentrismo e América Latina. In Lander, Edgardo. A colonialidade do saber: eurocentrismo e ciências sociais. CLACSO, 227-278.

Quijano, Aníbal. (2010). La crisis del horizonte de sentido colonial/moderno/eurocentrado. Revista Casa de Las Américas. Cuba, 259-260, 415.

Santos, Boaventura de Sousa. (2009). Para além do pensamento abissal: das linhas globais a uma ecologia de saberes. In Santos, Boaventura de Sousa \& Meneses, Maria Paula (Org.). Epistemologias do Sul. Coimbra, Portugal: Almedina, 23-71.

Saviani, Dermeval, Rama, German \& Weinberg, Gregório. (1996). Para uma História da Educação Latino Americana. Campinas, Brasil: Autores Associados. 
Schueler, Alessandra Frota Martinez de. (2014). Educação, experiência e emancipação: contribuições de e. P. Thompson para a história da educação. Trabalho Necessário, Niterói, UFF, 12, 18.

Spivak, Gayatri Chakravorty. (2010). Pode o subalterno falar?. Tradução de Sandra R. Goulart Almeida, Marcos Feitosa, André Feitosa. Belo Horizonte, Brasil: Editora UFMG.

Streck, Danilo Romeu. (2007). Educação em Nossa América: textos selecionados. ljuí: Unijuí.

Streck, Danilo Romeu, Moretti, Cheron Zanini \& Adams, Telmo. (2010). Pensamento pedagógico em nossa América: uma introdução. In Fontes da pedagogia latino-americana: uma antologia. Belo Horizonte, Brasil: Autêntica, 1936.

Walsh, Catherine. (2012). Interculturalidad crítica y (de)colonialidad: ensayos desde Abya Yala. Quito, Equador: Abya Yala.

Weinstein, Barbara. (2003). História sem causa? A nova história cultural, a grande narrativa e o dilema pós-colonial. História, Franca, 22(2), 185-210.

\section{Nota}

\footnotetext{
${ }^{1}$ British Raj refere-se à dominação inglesa no subcontinente indiano entre os anos de 1858 e 1947, na região comumente conhecida como Índia na contemporaneidade, possui áreas diretamente administradas pelo Reino Unido.
} 